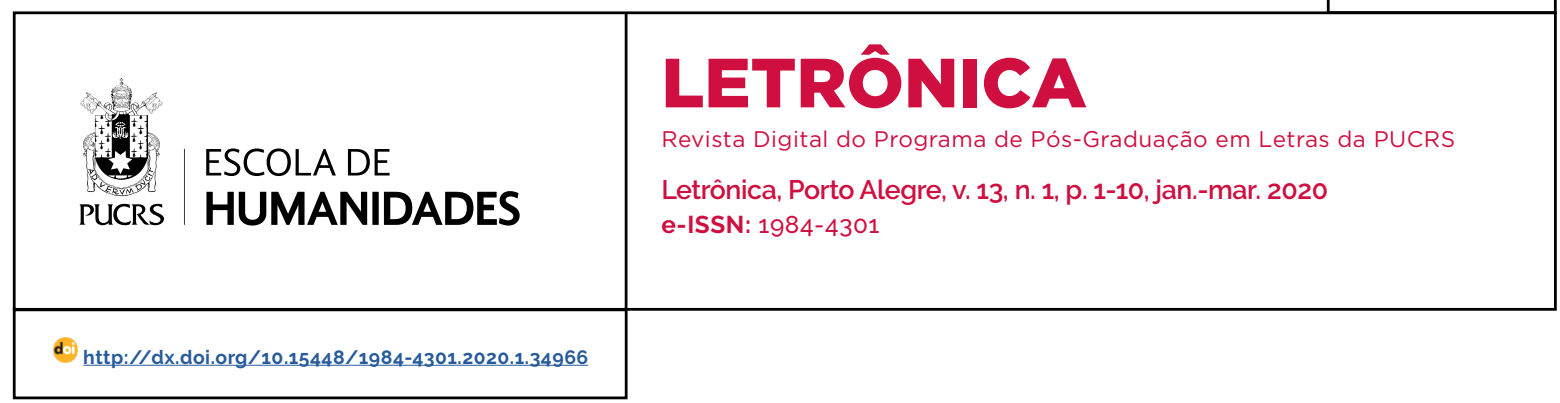

\title{
Isabel Allende e Marcela Serrano: vozes chilenas na literatura latino-americana
}

\author{
Isabel Allende and Marcela Serrano: Chilean voices in Latin American Literature \\ Isabel Allende y Marcela Serrano: voces chilenas em la literatura latinoamericana
}

\section{Cecil Jeanine Albert \\ Zinani $^{1}$}

orcid.org/0000-0002-8656-8865

cezinani@terra.com.br

Recebido em: 21 nov. 2019

Aprovado em: 22 nov. 2019.

Publicado em: 7 abr. 2020.
Resumo: Este artigo tem como objetivo examinar elaborações de gênero, como categorias do feminino, no conto "Duas palavras", de Isabel Allende, e no romance Nossa Senhora da Solidão, de Marcela Serrano. Procedeu-se a uma revisão de conceitos de crítica feminista aplicados aos textos, enfatizando a questão da linguagem como eixo norteador. Verificou-se a pertinência do exame da especificidade da escritura e da leitura como modalidades de permanência da história da comunidade, no caso do conto, e a chave para decifrar o enigma, no caso do romance. Também é importante constatar a relevância dessas atividades, na medida em que operam tanto na constituição da identidade quanto na emancipação do sujeito feminino.

Palavras-chave: Duas palavras. Nossa Senhora da Solidão. Leitura e escritura. Emancipação.

\begin{abstract}
This article aims to examine gender elaborations, as categories of the female, in Isabel Allende's short story "Two Words", and in Marcela Serrano's novel Our mother of Solitude. A review of the concepts from the feminist critics that are applied to texts was carried out, emphasizing the language as the main topic. It was found as pertinent to examine the specificity of the writing and the reading as strategies for the permanence of the history of a community, in the case of the short story, and as the key to solve an enigma, in the case of the novel. It is also important to point out the relevance of these activities, as they operate both on the identity construction process and on the emancipation of the female character. Keywords: Duas palavras. Nossa Senhora da Solidão. Reading and writing. Emancipation.
\end{abstract}

Resumen: Este artículo tiene como objetivo investigar elaboraciones de género, como categorias del femenino, en el cuento "Dos palabras", de Isabel Allende, y en el romance Nuestra Señora de la Soledad. Se ha procedido a una revisión de conceptos de la critica feminista aplicada a los textos, poniendo énfasis a cuestión del lenguaje como eje que la nortea. Se ha verificado la pertinencia del examen de la especificidad de la escritura y de la lectura como modalidades de permanencia de la historia de la comunidad, en el caso del cuento, y la clave para descifrar el enigma, en el caso del romance. También es importante constatar la relevancia de esas actividades, en la medida en que actúan tanto en la constitución de la identidad cuanto en la emancipación del sujeto femenino. Palabras clave: Dos palabras. Nuestra Señora de la Soledad; Lectura y escritura. Emancipación femenina. 


\section{Introdução}

"En América Latina, las prácticas democratizadoras del feminismo se han entendido como un trabajo político comunitario en la tarea de restablecer las redes de solidaridad; en esa resistencia a los deterioros de la crisis, la fuerza creativa de lo femenino puede devolvernos certidumbre también en la literatura.

Si la misma noción de "mujer" es una fantasia masculina (una construcción social e ideológica que dice más de nuestros medios que de la mujer misma), estas y otras escritoras están ya demostrando su capacidad

para subvertir y descentrar las codificaciones que pasan por lo real". (Julio Ortega)

A epigrafe acima aponta para a superação, se não total, pelo menos parcial do problema que a produção literária feminina sofreu ao longo do tempo, a invisibilidade. Isso está ligado, novamente recorrendo à epigrafe, ao conceito de mulher que vigorou desde tempos primordiais, produto de um ponto de vista expresso com muita propriedade por Simone de Beauvoir (1980), quando afirma que o homem é o Um e a mulher, o Outro. $\mathrm{Na}$ medida em que se constitui como o outro, jamais se materializará como sujeito, permanecendo na posição descartável de objeto. Esse enfoque, ainda que seja uma construção ideológica, é biologicamente insustentável por absurdo, tendo em vista que esse outro faz parte de uma totalidade cujos polos são indispensáveis (BEAUVOIR, 1980).

Ainda que, no decurso dos tempos, muitas mulheres tenham-se destacado por suas posições nos terrenos da política, da educação, das artes, permaneceram em um lugar secundário, quando não no completo esquecimento, haja vista o espaço das escritoras nas histórias da literatura, ou mesmo, os subterfúgios a que precisaram recorrer, a fim de marcar sua presença fora das paredes do lar.

Na América Latina não foi diferente. Na década de 60 do século XX, ocorreu o que se denominou como o boom da literatura latino-americana, constituído, inteiramente por nomes masculinos: Gabriel Garcia Márquez, Vargas Llosa, Júlio Cortázar, Carlos Fuentes, Roa Bastos entre outros. Nesse elenco, não aparece nenhum nome de mulher, uma vez que a literatura produzida por autoras sempre foi rotulada de "feminina". De acordo com Navarro, essa modalidade de literatura, via de regra, foi considerada inferior, preocupada com problemas domésticos ou intimos e, por isso, não merecendo ser colocada na mesmo posição da literatura produzida por homens, cujo envolvimento com questões 'importantes', isso é, com a política, história e economia foi sempre assumida sem discussão. O resultado disso é que editores ansiosos por publicar obras escritas por homens não se dispunham a fazer o mesmo com as mulheres romancistas (NAVARRO, 1995, p. 13).

As autoras somente irão aparecer cerca de 20 anos depois, preocupando-se com temáticas igualmente relevantes, aliadas a uma técnica narrativa apurada, apresentando uma ficção de muita qualidade, é o caso de escritoras como Gioconda Belli, Rosário Ferré, Elsa Osório, Laura Restrepo, Julia Alvarez, para citar apenas algumas.

Isabel Allende e Marcela Serrano são autoras de alentada bibliografia, com expressiva recepção por parte dos leitores, ainda que enfrentem problemas com a crítica de seu país que as considera escritoras de pouca densidade literária. No entanto, ambas receberam premiações bastante expressivas. Allende recebeu, entre outros, o Prêmio Nacional de Literatura do Chile; Serrano, entre outros, recebeu o Prêmio de Literatura Sor Juana Inez de la Cruz, considerado uma distinção muito relevante conferida a escritores em língua espanhola.

Embora tenha nascido no Peru, em 1942, Allende mudou-se com a família para o Chile ainda criança, local no qual transcorreu sua juventude, considerando-se, por esse motivo, como chilena. Com a morte de seu tio Salvador Allende e o início do governo Pinochet, a família transferiu-se para a Venezuela, onde a autora começou a escrever. Sua primeira obra, A casa dos espíritos, de 1982, obteve muito sucesso, sendo, posteriormente, adaptada para o cinema. Tendo produzido mais de 20 romances, também escreveu contos e peças de teatro, residindo, atualmente, nos Estados Unidos.

Marcela Serrano nasceu em Santiago, Chile, em 1951, filha de uma romancista e de um engenheiro e ensaista, estreou nas letras em 1991, com a obra Nós que nos amávamos tanto, com a qual recebeu o Prêmio Sor Juana Inez de la Cruz. Além de romances, escreveu, também, contos. 
O interesse nessas autoras decorre da possibilidade de verificar aspectos, na arquitetura de suas obras ficcionais, que podem ser identificados como elaborações de gênero, enquanto categorias do feminino, na medida em que constroem personagens que conseguem subverter condições impostas por uma sociedade patriarcal e afirmar sua identidade, tornando-se sujeito de sua história. Além disso, as temáticas desenvolvidas apresentam uma abordagem especifica, tendo em vista que se trata de ficção cujas narradoras são mulheres, privilegiando o ponto de vista feminino. Nesse sentido, pretende-se examinar um texto de cada autora, evidenciando que a superação da invisibilidade feminina pode ocorrer pelo uso artístico da palavra na apresentação de temáticas relevantes na contemporaneidade.

\section{Eva Luna: autora e personagem}

Desde tempos antigos, o lugar de fala pertenceu ao homem, tendo em vista que era detentor do espaço exterior. Uma vez que a mulher era segregada no "aconchego do lar", confinada aos afazeres domésticos e ao cuidado com a prole, transformou-se em um ser sem voz, pois não havia motivo para que fosse ouvida, já que nada de relevante poderia ocorrer em seus domínios. Ainda que houvesse, ao longo da história, algumas mulheres que conseguissem ser ouvidas, isso constituia uma exceção, jamais a regra. Atualmente, a presença da mulher no espaço público começa a se modificar, embora haja ainda um longo caminho a percorrer. A esse respeito, Navarro pondera:

\begin{abstract}
Embora as chances de participação das mutheres nas esferas politicas e econômicas da sociedade tenham sido levemente modificadas em tempos recentes, quando se examinam evidências empiricas, ainda se pode afirmar que a mulher latino-americana em geral ainda permanece em silêncio, sem voz e usualmente sem acesso a práticas discursivas e a práticas culturais (NAVARRO, 1995, p. 14).
\end{abstract}

Situada em uma sociedade de cunho patriarcal, a luta pela autonomia e pelo direito de usar sua voz revestiu-se de grandes dificuldades, haja vista o passado de guerras, o caudilhismo e os regimes de exceção que se instalaram da América Latina, conformando uma cultura em que o valor relevante era a violência, assim, privilegia-se o sexo que mata em detrimento daquele que dá a vida. Nesse contexto, dificilmente, uma mulher poderia ser ouvida, muito menos, ser lida. Portanto, para chegar à escrita, um longo caminho teve que ser percorrido, desde a luta pelo acesso à educação até a conquista do voto e da emancipação civil. Explica-se, assim, a defasagem entre o número de escritores e de escritoras em atividade, diferença essa muito maior quando se investiga a presença/ausência feminina nas histórias da literatura.

Allende, cujas obras apresentam muitas reedições, é uma escritora que ultrapassou a invisibilidade, com temáticas que apresentam o sujeito feminino e sua luta pela emancipação. Tanto no romance Eva Luna quanto na obra Contos de Eva Luna, a constituição da mulher como sujeito acontece por meio da linguagem. É na apropriação das condições materiais para a produção da escrita que Eva Luna como também as personagem criadas por ela, na condição de "inventora de histórias", constroem suas identidades e tornam-se sujeitos de seus destinos.

Quem detém a palavra supera a invisibilidade e se constitui social e subjetivamente. É o que ocorre tanto no romance (1987) quanto no livro de contos de Allende (2014), espécie de continuação do romance. Eva Luna, qual moderna Scherezade, se apropria da palavra e com ela reinventa a sua vida e constrói o seu futuro. Personagens e situações entremeiam-se, possibilitando que Eva Luna construa sua trajetória de jovem analfabeta a autora de novelas de televisão.

A intertextualidade é um recurso narrativo utilizado por Allende para compor o livro de contos, tendo em vista que o romance é narrado por Eva Luna, a protagonista, que assim se apresenta: "Chamo-me Eva, que quer dizer vida, segundo um livro que minha mãe consultou para escolher meu nome" (ALLENDE, 1989, p. 7). Já em Contos de Eva Luna, Eva não é mais protagonista, apenas a narradora que atende a 
um pedido de Rolf Carlé (também personagem do romance) para que ela the conte um conto, estabelecendo-se o seguinte diálogo: "- Como queres que ele seja? - Conta-me um conto que nunca tenhas contado a ninguém" (ALLENDE, 2014, p. 12). Nesses contos, Eva Luna retoma personagens e situações do romance, tais como 0 turco Riad Hallabi e a Mestra Inês que aparecem no conto "O ouro de Tomás Vargas". Ambas as obras contêm epigrafes retiradas de As mil e uma noites e referem-se à eloquência da filha do vizir. Em Contos de Eva Luna, a epigrafe remete à solicitação da irmã, para que Sherezade conte uma história que lhes ajude a passar a noite. De certa maneira o conto "Duas palavras", contado por Eva Luna a Rolf Carlé, recupera a trajetória da personagem narradora do romance. Belisa Crepusculário, protagonista do conto, depois de enterrar pais e irmãos, resolveu seguir na direção do mar "para ver se, na viagem, conseguia enganar a morte" (ALLENDE, 2014, p. 14), pois onde se encontrava não havia alternativas de sobrevivência. O espaço social era tão escasso que não havia nome para os filhos, uma vez que a sobrevivência à fome e à fadiga atávicas consumia todas as energias.

A escolha do nome significou um segundo nascimento, pois, ao se nomear, estabelece a sua identidade e prenuncia sua futura profissão vender palavras. O nome Beliza remete a radicais diferente: bele, de beleza ou bele, de guerra. Por meio de sua luta pela sobrevivência, descobre a beleza das palavras, com as quais exercerá seu poder de transformação. Crepusculário apresenta conotação de luz, claridade para as pessoas, assim também lembra o renascer do sol a cada dia. Após Beliza descobrir que as palavras não tinham dono e que poderia apropriar-se delas, "vender palavras pareceu-lhe alternativa decente" (ALLENDE, 2014, p. 15) a se prostituir ou empregarse como criada. Assim definiu sua profissão.

A descoberta da escrita ocorre acidentalmente, ao deparar-se com a página esportiva de um jornal e indagar o significado daquelas manchas que apareciam no papel. Descobrindo as letras, pagou a um padre para que a alfabetizasse. Com o restante do dinheiro, comprou um dicionário, leu-o inteiramente e, posteriormente, jogou-o ao mar, porque "não era sua intenção cansar os clientes com palavras enlatadas" (ALLENDE, 2014, p. 15). Possivelmente, essa consciência da linguagem estava na base de seu sucesso profissional.

A descoberta da escrita possibilita a Beliza a realização de sua função social: contando histórias, de povoado em povoado, mantém os laços sociais e contribui para a continuação da história. Escrevendo cartas, consegue sobreviver, pois comercializa seu ofício, evidenciando a importância de uma profissão, o que constitui outro aspecto relevante para a construção de sua identidade e para sua emancipação.

Beliza estipulava um preço para a venda de sua mercadoria - as palavras -, acrescida de um bônus, conforme o volume da venda que efetuava. Aos poucos, sua fama cresceu, tornando-se bastante popular e sendo muito aguardada em todos os povoados pelos quais andava, até ser raptada pelos homens do Coronel, homem poderoso cujo bando espalhava o terror por onde andava, seguindo o modelo dos caudilhos que infestaram a América Latina. O Coronel queria que ela escrevesse um discurso, pois desejava tornarse presidente, não pelo uso da violência, mas por escolha dos eleitores. Ainda que pudesse tomar o que desejasse por meio da violência, intimamente, desejava ser amado pelas outras pessoas.

Realizada a tarefa, Beliza leu para o Coronel (ele era analfabeto) e seus homens o discurso que escrevera, deixando-os mudos pela força do que ouviam, pois eram palavras que cativavam. o Coronel pagou o serviço e recebeu duas palavras como bônus. No discurso, Beliza utilizou as palavras adequadas para falar à percepção das mulheres e à inteligência dos homens. Essa constatação não deixa de apresentar traços de ironia, tendo em vista que realiza um trabalho racional, comprovando que uma mulher pode realizar trabalhos intelectuais. A emoção, caracteristica feminina, não domina Beliza. $\mathrm{Na}$ conclusão do conto, com a submissão do Coronel às palavras de Beliza, evidencia-se a perda de sentido do poder da força, pois é por meio da 
palavra que a jovem exerce o poder simbólico, podendo representar o outro. Em relação à questão feminina, há uma desconstrução do estereótipo: homem racional $X$ mulher emocional. Sem abrir mão de sua feminilidade, Beliza consegue realizar uma atividade intelectual, enquanto o Coronel, também sem abrir mão de sua hombridade, deseja ser amado, ou seja, há uma inversão da equação: mulher racional $X$ homem emocional. Esse é um dos aspectos marcantes do conto "Duas palavras".

Beliza, da mesma maneira que Eva Luna, constitui o protótipo de mulher vencedora. Sozinha no mundo, não soçobra, porque a pulsão de vida norteia seus passos, assim, atravessa a pé uma região inóspita, pois não deseja morrer. Não tem nome, escolhe um para si, selando sua identidade. Para sobreviver, necessita de um profissão, dessa maneira, opta por vender palavras. Exerce seu trabalho, primeiramente, contanto historias de forma oral, depois de alfabetizada, passa a escrever, registrando a história, não apenas pessoal, mas das comunidades que a aguardam ansiosamente. Na verdade, a linguagem, na forma oral ou escrita, constitui a salvação de Beliza, caminho que ela descobre e por meio do qual se realiza pessoal e profissionalmente.

\section{Marcela Serrano e o romance policial}

Considerado "literatura de massa", o romance policial obedece a algumas normas, sem as quais, perde a característica básica de seu gênero, ou seja, deixa de ser romance policial. Todorov (1979) considera que o melhor romance policial é aquele que melhor se adapta às regras que conformam o gênero. Se houver subversão às normas, a obra sai do gênero literatura de massa policial constituindose em literatura, simplesmente. Na descrição do romance policial, Todorov (1979) aponta que toda a narrativa policial, também denominada de enigma, é composta de duas histórias, a história do crime e a história da investigação nessa ordem. A história do crime é a base para a do inquérito, havendo pouco, ou nenhum contato entre as histórias. As personagens da segunda história apenas descobrem o que ocorreu. Para Todorov
(1979, p. 96), "a história do inquérito goza pois de um estatuto todo particular [...] ela consiste, de fato, em explicar como essa narrativa pode ser feita, como o próprio livro é escrito".

Ao discorrer sobre as teses que norteiam a escrita do conto, Piglia (1994, p. 37) apresenta a primeira que diz: "um conto sempre conta duas histórias". Continua:

O conto clássico (Poe, Quiroga) narra em pri-
meiro plano a história 1 [...] e constrói em segre-
do a história 2 [...]. A arte do contista consiste
em saber cifrar a história 2 nos interstícios da
história 1. Uma história visivel esconde uma
história secreta, narrada de um modo elíptico
e fragmentário (PIGLIA, 1994, p. 37).

Como está demonstrado, a ocorrência de duas histórias na mesma narrativa não é prerrogativa do romance policial. O autor exemplifica com o embrião de um conto e demonstra como ocorre o entrelaçamento das duas histórias em Borges, Kafka, Tchekov, Katherine Mansfield, Hemingway. $\mathrm{Na}$ verdade, nenhum desses autores pode ser considerado como escritor de literatura de massa.

Ainda que haja um bom número de autoras que produzem narrativas policiais, essa modalidade literária foge ao que se convencionou chamar de literatura feminina, como aliás, romances que explorem temáticas sociais muito vigorosas, como a questão da ditadura na República Dominicana, abordada por Julia Alvarez, que apresenta a saga das irmãs Mirabal em Tempo das borboletas (2001); ou Elsa Osorio que, em Há vinte anos, Luz (1999), discute a problemática dos bebês raptados e o movimento das mães e avós da Praça de Maio, na Argentina; ou, ainda, Isabel Allende e Marcela Serrano que ambientem os romances no período da ditadura de Pinochet, no Chile, respectivamente, nas obras De amor e de sombra (1986) e Nós que nos amávamos tanto (2005), discutindo as consequências daquele regime autoritário na vida das pessoas. Além da temática forte, essas obras se caracterizam pelo apuro da técnica narrativa, entre outros aspectos, alternando a voz narrativa, assim como o ponto de vista.

Luisa Valenzuela, escritora portenha, faz uma incursão no gênero policial noir, em Romance negro com argentinos (2001), obra de grande 
densidade literária, em que cifra um assassinato cometido em Nova lorque (primeira história) com a ditadura militar argentina (segunda história). Assim, em Nossa Senhora da Solidão, Marcela Serrano escreve um romance policial com alguns ingredientes básicos - detetive e vítima -, fugindo aos lugares comuns do gênero, ao adicionar elementos que transformam a narrativa, tais como a importância da leitura, a possibilidade de colocar-se no lugar do outro para solucionar o enigma e a focalização no modo de ser feminino.

O romance desdobra-se entre Chile e México, pois foi nesse pais que muitos chilenos se exilaram durante a ditadura. A história número um refere-se ao desaparecimento da escritora Carmen L. Ávila, esposa do reitor da Universidade. Tematizando a solidão e o abandono, o romance é narrado pela protagonista da história dois, Rosa Alvallay, profissional pertencente a uma agência de investigações particular. A escolha da investigadora ocorre por dois motivos, primeiro, viveu no México, onde frequentou a Universidade, por ocasião de seu exilio, acompanhando o marido. O segundo, é por ser uma mulher como C. L. Ávila.

A questão de gênero apresenta uma importância capital, pois a investigadora, sendo mulher, tem maior facilidade de colocar-se no lugar da desaparecida, uma vez que a identidade de gênero possibilita que se abra maior número de alternativas. Nesse aspecto, é valorizada a experiência feminina. Outro aspecto interessante ocorre quando Rosa consegue traçar o perfil de Carmen: escritora famosa, com inúmeras experiências em diferentes latitudes, não se importa com o governo da casa, deixando as decisões a cargo dos serviçais. Segundo a governanta Giorgina, essa atitude deve-se ao fato de que a esposa do reitor não sabe mandar, pois estava sempre ocupada em escrever, e, de acordo ainda com a serviçal, escrever não é trabalho. Carmen organiza um escritório especial para si, completamente diferente do restante da casa, no qual se isola para escrever, viaja, profere palestras em congressos, configurandose um sujeito forte, autônomo, emancipado. No entanto, seu comportamento é desvalorizado pelos criados que precisam ser mandados e não reconhecem seu trabalho; pelo marido que critica suas atitudes politicas com o pretexto de que the falta consistência teórica. Percebe-se, assim, a ambiguidade no tratamento relativo ao gênero: a toda valorização corresponde um movimento em sentido oposto. O mesmo ocorre com a investigadora Rosa Alvallay que sofreu muitos percalços para conseguir escrever sua própria história, pois "aquelas que procuram sua autodeterminação quase sempre pagam caro por isto: a palavra liberdade aplicada a uma mulher geralmente é mentira" (SERRANO, 2003, p. 93). Na agência de investigadores em que trabalha, em geral, para os casos importantes, são designados homens.

A conversa com Giorgina possibilita o delineamento da vida familiar de Carmem, enquanto o marido apenas repete o que já havia aparecido nos jornais. Na opinião do reitor, Carmen foi sequestrada por um movimento guerrilheiro e está viva. A filha do reitor não mantém bom relacionamento com a madrasta, considerando-a uma pessoa egoísta que se ocupa apenas consigo mesma, cansada de reinventar-se diariamente. Decisivamente, não era a esposa ideal para um homem público como seu pai. Na sua opinião, Carmen está viva, porque tem muita imaginação e poderia, facilmente, descobrir uma forma de evadir-se, sem deixar vestígios, de uma vida tediosa e desagradável. Jill, a amiga norte-americana, acha que Carmen está morta. Ambas moraram no México e viviam da venda de artesanato. Segundo a amiga, elas tinham um vida boêmia, pois Carmen dançava e cantava em bares. A venda do primeiro livro de Carmen gerou os fundos necessários para uma viagem das duas amigas à Índia. O traço marcante da entrevista de Jill é o profundo abandono em que vivia a autora. O mesmo traço perpassa a entrevista que Carmen concedeu a um periódico em Madri, no qual relata, entre outros fatos, que os pais a abandonaram, quando era pequena, para irem viver na Índia, tendo sido criada por sua tia norte-americana Aunt Jane.

A ideia de abandono e de instabilidade é enfatizada pelo escritor Martín Robledo Sánchez, amigo de Carmen e autor favorito da narradora, ao 
remeter à história da bisavó da escritora que era cigana, atribuindo ao fator genético os desajustes da autora. Justifica seu posicionamento ao afirmar: "Nunca conheci ninguém que sofresse tanto por se sentir prisioneira da formalidade existente; ela deveria ter sido uma habitante da selva... ou dos bosques... nunca de uma cidade rígida e pouco original como Santiago" (SERRANO, 2003, p. 34). Não imagina o que possa ter-lhe ocorrido, na sua opinião o mais coerente seria o suicidio, mas faltaria um motivo. 0 que não se justifica, uma vez que Carmen era muito infeliz. Além disso, Sánchez revelou que a escritora detestava a protagonista de seus romances, Pamela Hawthorne, porém não conseguia libertar-se dela.

Além de interrogar as pessoas que tinham relação com Carmen, Rosa compra os cinco romances da escritora e os relê. Evidencia-se então o que Culler (1997, p. 56) denomina "ler como mulher", tendo em vista que particulariza a experiência feminina da leitura, considerando-a "uma fonte de autoridade para suas respostas como leitora". Essa leitura gendrada instaura uma hermenêutica do texto que possibilita a construção de novos significados, tendo em vista que desconstrói estereótipos de gênero, promovendo novos questionamentos e buscando respostas condizentes com a posição dessa leitora que se constituiu na diferença de gênero e de sentido.

Nessa perspectiva de leitura, Rosa examina os romances a partir da heroina Pamela Hawthorne, a investigadora dos romances policiais de Carmen, que esboça posicionamentos feministas, como o excerto seguinte:

Pamela Hawthorne sustentava - sem dizer de maneira explicita - que as mulheres eram mais argutas no campo da investigação criminal que os homens. Não que ela fosse dessas feministas que acham que as mulheres fazem tudo melhor, nada disso. Aludia simplesmente a certa percepção não objetiva que nós mulheres, temos em relação a qualquer verdade. Intuo ao que ela se refere (SERRANO, 2003, p. 52, grifo do autor).

A leitura dos romances constitui-se, dessa maneira, no elemento-chave para a decifração do enigma.

Outro tópico chama a atenção da investigadora: as dedicatórias. Considerando que C. L. Ávila escreveu cinco romances em doze anos, é provável que esses indices paratextuais possam revelar alguns elementos sobre as transformações ocorridas. Os livros são dedicados ao marido (Tomás), ao filho (Vicente), à amiga Jill e à Aunt Jane. No entanto, o primeiro romance, Os mortos não têm nada a dizer, de 1984, traz como dedicatória: "Ao meu amor, meu tolo, meu menino" (SERRANO, 2003, p. 26), considerada um tanto impudica pela narradora. $\mathrm{Na}$ verdade, quando é descoberta a identidade do destinatário, o mistério é desvendado.

Além de escritora, Carmen é uma grande leitora, sua biblioteca é imensa, portanto, é em um livro que deve ser encontrada a explicação do ocorrido. Esse livro é A loba, do mexicano Santiago Blanco, no qual "a ação se baseia nos complicados mecanismos da mulher para disfarçar e combater esse desamparo em seu interior, diante do olhar impotente do homem que a ama" (SERRANO, 2003, p. 112). Nessa obra, Blanco inspira-se em Carmen Lewis Ávila, apresentando aspectos de sua vida. No início do livro, escreve Santiago: "Uma doida. Era uma doida. A mulher de vestido vermelho dançando em cima daquela mesa era um doida, foi o que the disseram" (SERRANO, 2003, p. 109). Rosa confirma com o reitor que essa mulher era, efetivamente, Carmen. Na verdade, a página em que Carmen é descrita abre o romance Nossa Senhora da Solidão. A filha do reitor utiliza as mesmas palavras também referindo-se a ela como doida. Blanco concorda que se inspirou em uma pessoa real. O capítulo da bailarina conclui com uma fantasia da personagem: "Ter uma casa em algum lugar do mundo. Pintada de azul" (SERRANO, 2003, p. 110). No último livro de Carmen, dedicado a sua amiga Jill, denominado Um mundo estranho, a autora refere-se ao caso verdadeiro do inglês James Thompson, comerciante de seda, que desapareceu na Tailândia sem deixar vestígios. A constatação de Carmen de que o escritor não narra o que já aconteceu, mas aquilo que está por vir, ou seja, tem uma visão prospectiva, é comunicada a seu amigo o também escritor Martín Robledo Sánchez, o que não deixa de ser uma antecipação dos planos da autora. 
Ainda no México, a entrevista com Santiago Blanco e a "visita" à casa pintada de azul em Oaxaca, onde vive uma pretensa colombiana chamada Lucia Reyes, concluem o perfil de Carmen, encerrando a história dois. Emerge então a história um: cansada de uma vida vazia, das traições do marido com as amigas da filha dele e com a possibilidade de reatar laços antigos com Santiago Blanco, Carmen, após o casamento de Vicente, seu filho, forja o próprio desaparecimento, inspirada no negociante de seda. Auxiliada por Santiago Blanco, compra a casa e a reforma para deixá-la a seu gosto. Por ocasião de sua viagem à Feira do Livro em Miami, aproveita a viagem de retorno, para desaparecer e, com um passaporte falso, refugiar-se no interior do México.

\section{Considerações finais}

Tanto o conto "Duas palavras" quanto o romance Nossa Senhora da Solidão apresentam como protagonistas mulheres fortes que conseguem subverter um contexto altamente desfavorável por meio do esforço e da tenacidade, emancipando-se social e financeiramente. Ambas narrativas apresentam um compromisso com a linguagem, como modalidade de reordenação das respectivas contingências.

Belisa se reinventa quando toma as rédeas de seu destino, partindo na viagem que a levaria a terras melhores do que aquela em que havia enterrado sua família. O passo seguinte é "ataviar-se" com um nome, constituindo sua identidade; em seguida, precisa descobrir um modo de ganhar a vida sem prostituir-se ou ser criada de alguém, descobre, então, as palavras. Ao apropriar-se das palavras, primeiro, apenas, contanto histórias, depois escrevendo, inventa sua profissão, com a qual se identifica. Sua trajetória, marcada pela superação da pobreza e do analfabetismo, comprova a força desse sujeito feminino que, por meio de sua luta e de escolhas adequadas, atinge a emancipação.

Rosa Alvallay e Carmen Lewis Ávila também concretizam suas metas, ainda que de forma diferente. Rosa leva a cabo uma investigação muito bem-sucedida. Utilizando a intuição feminina, apontada pela personagem de C. L. Ávila, Pamela Hawthorne, resolve o enigma do desaparecimento da autora. Nesse sentido, a ficção torna-se uma importante fonte de informações, tanto a escrita por Carmen quanto a de outros escritores como Martín Robledo Sánchez, Santiago Blanco e Octávio Paz, citado pela autora em sua entrevista. Lendo com atenção as dedicatórias, as epígrafes e as entrelinhas dos romances, assim como a entrevista concedida pela escritora para um periódico madrilenho, Rosa consegue descobrir as pistas que conduzem ao paradeiro da autora desaparecida. No entanto, o que poderia consistir em seu maior triunfo profissional, se fosse revelado, não se concretiza, pois ela prefere respeitar a escolha de Carmen, mantendo a ficção de seu desaparecimento, ao dar o caso por encerrado.

Carmen, inspirada no inglês que desapareceu na Tailândia, planeja passo a passo seu sumiço, porque, ainda que com o marido - reitor Tomás Rojas - tenha obtido a estabilidade de uma família organizada, a vida tornou-se muito desagradável, devido às contínuas traições, ao descaso com seu trabalho. Dessa maneira, planeja detalhadamente suas ações e, aproveitando a oportunidade que tem de participar da Feira do Livro em Miami, a viagem de retorno não se concretiza. Não volta para o Chile, indo para o México com um passaporte falso, obtido por meio de Luís Benitez, um guerrilheiro mexicano, que havia sido muito próximo. De certa maneira, Carmen concretiza o que sua enteada havia dito, que ela tinha bastante imaginação para arquitetar seu próprio desaparecimento, pois era escritora, e sua vida era um tédio. Afinal de contas, ela era uma romancista.

Dois aspectos merecem destaque em Nossa Senhora da Solidão: leitura e escritura. Foi a leitura que propiciou os indícios para a que Rosa localizasse a escritora. No entanto foi necessário o exercicio de uma leitura gendrada, ou seja, uma modalidade específica de leitura que privilegie a experiência feminina, ou como enfatiza Culler (1997), precisou ler como mulher, o que significa a necessidade de mobilizar sua experiência de vida, que é diferente da experiência masculina, 
para conseguir perceber o que havia por trás do texto. Ou seja, precisou ler como se fosse um palimpsesto, ler a escritura sob a escritura. Essa, por sua vez, continha os elementos que possibilitaram essa leitura específica, nos romances dos autores indicados, os quais apresentavam indicios que possibilitaram a reconstrução da trajetória da escritora, e, assim, o entendimento de seu modo de pensar. Feito isso, a solução do mistério tornou-se uma questão de método, o que Rosa dominava bem.

Tanto no conto quanto no romance, o papel do escritor é destacado, como algo específico de determinados seres humanos. Beliza, ao redigir o discurso para o Coronel, consegue mudar a história daquela região, tendo em vista a repercussão do texto que escreveu. As pessoas que fugiam apavoradas com a aproximação do bando do Coronel, agora o recebiam com festas e flores. Ainda que possa ser uma atividade pouco valorizada como enfatizam determinadas personagens de Nossa Senhora da Solidão, tais como Giorgina, a empregada, e o próprio reitor, a escrita foi fundamental não somente para Beliza e o Coronel, personagens de "Duas palavras", como para a investigadora e a escritora. O escritor Martín Robledo Sánchez ressalta o equívoco do posicionamento de Giorgina e do reitor, quando comenta: "Pode-se deixar um dia de ser reitor, você sabe, mas não de ser escritor" (SERRANO, 2003, p. 33). É o que percebe Rosa, quando entra, sorrateiramente, na casa de Lucia Reyes, e encontra uma folha ao lado do computador com o título: Capítulo Quarto. Encerra sua reflexão, observando que: "Talvez o romance noir tenha morrido, Pamela Hawthorne tenha morrido, C. L. Ávila tenha morrido, mas não a ânsia de inventar histórias e de contá-las" (SERRANO, 2003, p. 156). É o que também move Eva Luna, protagonista do romance e narradora dos contos.

Em Nossa Senhora da Solidão, evidenciase outro aspecto importante: a solidariedade feminina. A amiga norte-americana Jill procura encerrar o assunto, afirmando que Carmen morreu, também não menciona o acidente que sofreram na Guatemala nem o fato de que, quando viveram no México, alugavam uma casa de propriedade do escritor Santiago Blanco, na verdade, pai de Vicente, o filho de Carmen. Daí a observação de Carmen em sua entrevista, quando relata o fracasso de seu primeiro amor e a constatação que: "O problema com os mexicanos é que nunca deixam de estar casados..." (SERRANO, 2003. p. 87). De fato, na época de seu envolvimento com Carmen, Santiago Blanco era casado. Rosa Alvallay abre mão do que poderia consistir no seu maior êxito profissional: encontrar C. L. Ávila, já que se tratava de uma escritora famosa, ou como ela afirma: "que o prestígio que eu ganharia resolvendo esse caso é alto, que a verdade nesta minha profissão é o bem mais apreciado" (SERRANO, 2003, p. 171). Preferiu, em nome da solidariedade feminina, respeitar a escolha da escritora, mantendo o sigilo de sua nova identidade, pois não gostaria de ser delatada por outra mulher "se algum dia a esperança chegasse a se aventurar em mim" (SERRANO, 2003, p. 171).

Subliminarmente, as obras promovem uma reflexão sobre a situação da mulher, subvertendo o discurso que encobre a ideologia dominante na sociedade: a condição subalterna das figuras femininas. Ainda que sem enfrentar os grupos detentores do poder, essas narrativas possibilitam que seja entrevista uma nova ordem advinda do poder simbólico que emana da palavra.

Tanto no conto de Isabel Allende quanto no romance de Marcela Serrano, é possivel evidenciar aspectos que marcam uma literatura gendrada. A problemática do feminino opera na construção de um discurso, embora racional, que valoriza a emoção e a intuição, como modalidades especificas do feminino. Nas obras focalizadas, o vetor de transformação é a palavra em suas múltiplas formas: contada, escrita, lida e falada. O signo linguístico enseja o desdobramento em múltiplos significados na construção das personagens, na subversão dos estereótipos de gênero, no estabelecimento de uma nova visão do mundo. O acesso à linguagem, operando no campo simbólico, viabiliza às personagens, além de constituir-se como sujeito, resgatar a memória e promover um novo sentido para a vida. 


\section{Referências}

ALLENDE, Isabel. Eva Luna. 3. ed. Tradução de Luisa Ibañez. Rio de Janeiro: Bertrand Brasil, 1989.

ALLENDE, Isabel. Contos de Eva Luna. 7. ed. Tradução de Rosemary Moraes. Rio de Janeiro: Bertrand Brasil, 2014.

ALLENDE, Isabel. De amor e de sombra. Tradução de Suely Bastos. São Paulo: Difel, 1986

ALVAREZ, Julia. No tempo das borboletas. Tradução de Lea Viveiros de Castro. Rio de Janeiro: Rocco, 2001.

BEAUVOIR, Simone. O segundo sexo: 1. Fatos e mitos. 4. ed. Tradução de Sérgio Milliet. Rio de Janeiro: Nova Fronteira, 1980.

CULLER, Jonathan. Sobre a desconstrução. Tradução de Patrícia Burrowes. São Paulo: Record: Rosa dos Tempos, 1997.

NAVARRO, Márcia. Por uma voz autônoma: o papel da mulher na história e na ficção latino-americana contemporânea. In: NAVARRO, Márcia (org). Rompendo o silêncio: gênero e literatura na América Latina. Porto Alegre: Ed. da Universidade/UFRGS. p. 11-55

OSORIO, Elsa. Há vinte anos, Luz. Tradução de Rubia Prates, colaboração de Sérgio Molina. Rio de Janeiro: Objetiva, 1999.

PIGLIA, Ricardo. Teses sobre o conto. In: PIGLIA, Ricardo. O laboratório do escritor. Tradução de Josely Vianna Baptista. São Paulo: Iluminuras, 1994.

SERRANO, Marcela. Nossa Senhora da Solidão. Tradução de Paulina Wacht e Ari Roitman. Rio de Janeiro; São Paulo: Record. 2003.

SERRANO, Marcela. Nós que nos amávamos tanto. Tradução de Luis Carlos Cabral. Rio de Janeiro: Record, 2005.

TODOROV, Tzvetan. Tipologia do romance policial. In: TODOROV, Tzvetan. As estruturas narrativas. Tradução de Leyla Perrone-Moisés. São Paulo: Perspectiva, 1979. p. 93-104.

VALENZUELA, Luisa. Romance negro com argentinos. Tradução de Paloma Vidal. Belo Horizonte: Autêntica, 2001.

\section{Endereço para correspondência}

Cecil Jeanine Albert Zinani

Rua Francisco Getúlio Vargas, 1130

CEP 95070-560

Caxias do Sul, RS, Brasil

\section{Cecil Jeanine Albert Zinani}

Cecil Jeanine Albert Zinani é Doutora em Letras Literatura Comparada (UFRGS); Mestra em Letras - Teoria da Literatura (PUCRS); Estágio Pós-Doutoral em Letras - Memória e História (PUCRS). Professora e pesquisadora nos Programas de Pós-Graduação em Letras e no Curso de Letras (UCS). Tanto a tese quanto o relatório do estágio transformaram-se em livros que versam sobre literatura e história da América Latina na perspectiva feminina: Literatura e gênero: a construção da identidade feminina e História da literatura: questões contemporâneas. Coordena o grupo de pesquisa $\mathrm{Mu}$ lher e Literatura, vinculado ao Diretório do CNPq como "Literatura: perspectivas e transformações". 